\title{
CADASTRO DAS ÁREAS NATURAIS PROTEGIDAS EM MINAS GERAIS
}

\author{
Regina M. F. Camargos (*) \& Mônica Torrent Lanna (**)
}

\begin{abstract}
The directory of Protected Natural Areas in the State of Minas Gerais presents data concerning the legally protected areas at federal and state levels as well as the municipalities involved in each area, its dimensions, especific laws and the institutions responsible for the management of these areas. These data are basic references for the development of environmental licencing of projects and also for the definition of aliquats of the Ecological State Taxe, regarding the protected areas. This study indicates the need for the establishment of a State Plan for the preservation of natural areas.
\end{abstract}

\section{CONSIDERAÇÕES INICIAIS}

Unidade de Conservação (UC) é a denominação brasileira para as áreas protegidas pelo Poder Público com a finalidade de resguardar espaços representativos dos recursos naturais do país. São definidas por instrumentos legais específicos que discriminam o tipo de uso indicado à unidade, seus limites, dimensão, municípios abrangidos e o organismo gestor. Diferenciam-se das áreas naturais dispersas, protegidas pela legislação geral ${ }^{1}$.

As unidades de conservação podem ser áreas de domínio público ou privado e, de acordo com seu nível de abrangência e sua função no planejamento global de áreas protegidas, estarão sob jurisdição federal, estadual ou municipal. São classificadas em diversas categorias de manejo, tais como: parques, estações ecológicas, reservas biológicas, áreas de proteção ambiental, segundo as diferentes vocações e funções que exercem dentro dos objetivos de conservação da biodiversidade.

A demarcação de unidades de conservação constituiu uma das principais estratégias utilizadas mundialmente para se atingir a sustentabilidade dos recursos vivos (Moore \& Ormazábal 1988). A conservação destes recursos, segundo a União Internacional para a Conservação da Natureza e dos Recursos Naturais, apresenta três objetivos específicos:

- manter os processos ecológicos e os sistemas vitais essenciais (exemplos: a regeneração e a proteção dos solos, a reciclagem dos nutrientes e a purificação das águas), dos quais dependem a sobrevivência e o desenvolvimento humanos;

- preservar a diversidade genética (toda a gama de material genético que se encontra nos organismos vivos do mundo inteiro), da qual dependem o funcionamento de muitos dos processos e sistemas acima mencionados, os programas de cruzamento necessários para a proteção e a melhoria das plantas cultivadas e dos animais domésticos e dos microorganismos, assim como boa parte do progresso científico e médico, da inovação técnica e da segurança das numerosas indústrias que utilizam os recursos vivos;

- assegurar o aproveitamento sustentado das espécies e dos ecossistemas (em particular da fauna silvestre, inclusive a aquática, das matas e das terras para pastagem) que constituem a base de sustento de milhões de comunidades rurais e de importantes indústrias (IUCN 1984).

Como se vê, a conservação da natureza está inserida no objetivo mais amplo da própria sobrevivência humana, uma vez que seus componentes e bióticos constituem a base de sustentação da vida e da economia humanas.

Em Minas Gerais, tal preocupação explicita-se, a partir da década de 30, na delimitação de diversas áreas protegidas, com um aumento considerável destas áreas nas últimas duas décadas. O Estado é considerado um exemplo de gestão de UC no país, em função do nível de implantação de algumas de suas unidades, tais como os parques estaduais do Rio Doce e Ibitipoca. No entanto, a análise do desempenho do conjunto das UC já criadas atesta a inexistência de planejamento global para a proteção dos biomas mineiros. Em função disto, persistem distorções detectadas, também, em nível nacional e mesmo internacional. Estas distorções podem ser compreendidas, basicamente, pela análise de Moore \& Ormazável (1988), dos dados das Nações Unidas referentes ao aumento de $47 \%$ do número de áreas naturais protegidas em mais de 120 países, entre

1- Existem instrumentos legais que protegem áreas naturais de forma geral, tais como: as Áreas de Preservação Permanente APP (Lei $n^{\circ} 4.771$ de 15.09.65, Art. $2^{\circ}$ e $3^{\circ}$, Decreto $n^{\circ} 33.944$ de 18.09.92, Art. $7^{\circ}$ ); as veredas (Lei $n^{\circ} 9.682$ de 12.10.88, Decreto $\mathrm{n}^{\circ} 33.944$ de 18.09.92, Art. $7^{\circ}$ e $8^{\circ}$ ); as áreas configuradas por conterem espécies imunes de corte por serem consideradas em vias de extinção (Lei no 4.771 de 15.09.65, Art. 14 Lei no 9.743 de 15.12.88: Ipê Amarelo, Lei no 10.883 de 02.10.92: Pequizeiro; entre outras); as áreas inseridas no bioma Mata Atlântica (Decreto $n^{\circ} 750$ de 10.02.93) etc. 
1972 e 1982, concluindo, que: “ao que pese o impressionante número de áreas protegidas criadas até esta data (1988) é preciso reconhecer que essas, em sua maioria, foram criadas com um critério oportunista e fragmentário. Estas áreas foram sendo definidas à medida que se iam apresentando oportunidades, mas sem um plano integral, desconhecendo um enfoque holístico no qual se estabelecesse a organização de um sistema de áreas silvestres, destinado a proteger eficaz e efetivamente os distintos ecossistemas e o patrimônio genético, que representam as espécies nativas de cada país, descartando as zonas não essenciais para tal efeito".

De fato, a inexistência de um plano estadual de unidades de conservação pode ser apontada como uma das principais lacunas na política de proteção da diversidade biológica em Minas Gerais. O mesmo acontece em nível nacional, apesar das inúmeras tentativas de se estabelecer o Sistema Nacional de Unidades de Conservação.

Um plano do sistema de áreas protegidas conceitua e discrimina as categorias necessárias para se atingir os objetivos da política de conservação, define os objetivos de manejo específicos para cada categoria, estabelece critérios para orientar a seleção de novas áreas a serem protegidas e critérios para analisar a validade das unidades existentes quanto à sua inclusão no sistema, sua classificação e necessidade de transferência para outras categorias (Milano 1988).

No sentido de dar início ao plano do sistema estadual, a Fundação Estadual do Meio Ambiente (FEAM) elaborou o Cadastro de Unidades de Conservação do Estado de Minas Gerais (CEUC), subsídio indispensável e prioritário ao desenvolvimento desse trabalho.

Este cadastro, obtido através do levantamento dos instrumentos legais de criação de UC, identifica, até dezembro de 1995, as unidades sob jurisdição federal e estadual, fornecendo os dados relativos à categoria de manejo, instituição gestora, legislação de criação, dimensões e municípios abrangidos ${ }^{2}$. Com a colaboração dos organismos gestores de UC, foram cartografados os limites das unidades, tendo como base as cartas do IBGE, escalas 1:50.000 e 1:100.000. Encontram-se em andamento os trabalhos de digitalização dos dados cartográficos que serão apresentados em formato vetorial.

Além de subsidiar o planejamento das UC no Estado e no país, este cadastro vem atender às demandas imediatas, tais como: oferecer referências ao licenciamento e monitoramento de atividades potencialmente degradadoras quanto à interveniência em áreas naturais sensíveis; possibilitar que as unidades de conservação sejam plotadas nas cartas oficiais; auxiliar no planejamento de projetos de desenvolvimento (expansão da malha rodoviária, ferroviária, entre outros).

Em dezembro de 1995 foi aprovada a Lei Estadual n 12.040 de 28.12.953 - "ICMS Ecológico", que dispõe sobre a compensação e o incentivo fiscal aos municípios que abriguem em seu território unidades de conservação, outros tipos de áreas naturais protegidas, e outros atributos ${ }^{4}$. O Cadastro de Unidades de Conservação de Minas Gerais fornece a dimensão das parcelas municipais abrangidas por UC federais e estaduais e áreas correlatas, discriminando o nível de restrição ao uso do solo inerente à categoria de manejo. Os dados contidos no cadastro viabilizaram o cálculo do índice de conservação do município, inserido no critério meio ambiente do ICMS.

Este cadastro deverá ser complementado com a inscrição das unidades de conservação de âmbito municipal e atualizado anualmente segundo a dinâmica de criação e reclassificação de UC federais e estaduais.

\section{DIMENSÃO PROTEGIDA}

Minas Gerais possui 67 áreas protegidas que cobrem 1.237.584 ha ou 2,12\% do seu território (dados de dezembro de 1995). Destas unidades, 41 eqüivalem a unidades de conservação de uso indireto, ou seja, áreas voltadas para a preservação integral dos recursos, que correspondem a $0,58 \%$ da superfície mineira ou 339.610 ha. As unidades de uso indireto são assim chamadas porque os "benefícios auferidos pelo homem, provenientes destas áreas, diferem daqueles ligados ao processo de produção econômica" (Milano 1988). O restante das UC é representado por unidades de uso direto, a exemplo das Áreas de Proteção Ambiental, voltadas para o manejo sustentado dos recursos. Estas equiivalem a 1,23\% do território, ou 714.407 ha. Somam-se a elas, as áreas de proteção de mananciais, ainda não classificadas como unidades de conservação, que são manejadas como as UC de uso direto, mantendo uma parcela com uso controlado e o restante com proteção integral ${ }^{5}$. Estas áreas de mananciais somam $0.31 \%$ do território protegido ou 183.567 ha e em Minas Gerais foram formalizadas como Área de Proteção Especial. Existem ainda 59.359 ha mineiros demarcados como Áreas Indígenas que, embora representem áreas restritas ao uso econômico dos recursos naturais, possuem objetivos diferentes das unidades de conservação. Os dados acima referem-se às áreas sob proteção federal ou estadual (Tabelas 1 e 2).

2 - Este cadastro foi parcialmente publicado no Diário Oficial da União em 29.12.95 através da Resolução nº 002/95.

3 - O ICMS Ecológico foi adotado pelo Paraná (Lei Estadual Complementar no 5.991 ) e por SãoPaulo (Lei Estadual no 8.510 de 29/12/93); o Rio Grande do Sul espera regulamentação da Lei no 9.850 que trata do assunto.

4 - O Estado de Minas Gerais incluiu também os critérios de saneamento ambiental, patrimônio cultural, área cultivada, programa de saúde, manutenção e desenvolvimento do ensino, população e dimensão do município, entre outros.

5 - As áreas de proteção de mananciais estão incluídas nas últimas propostas para o Sistema Nacional de Unidades de Conservação, como Reserva Produtora de Água, requerendo, neste caso, a dominialidade pública dos terrenos atingidos. 


\section{CATEGORIAS DE MANEJO}

Minas Gerais tem se remetido à legislação federal para a criação de suas áreas protegidas. A legislação vigente foi instituída de forma isolada para cada categoria de manejo (Quadro 1 e 2), sendo que os estudos desenvolvidos a partir de 1979, no sentido de se definir uma gama de categorias adequada à realidade brasileira, ainda não foram absorvidos juridicamente ${ }^{6}$.

As Unidades de Conservação federais e estaduais estão distribuídas, no Estado, nas seguintes categorias de manejo: Parque (Federal, Estadual), Floresta
Nacional, Estação Ecológica, Área de Proteção Ambiental, Reserva Biológica e Reserva Particular do Patrimônio Natural. Existem ainda áreas protegidas com as denominações de Área de Proteção Especial, além de Áreas declaradas como de Preservação Permanente (Figura 1).

A gestão dessas unidades está a cargo do Instituto Brasileiro do Meio Ambiente e dos Recursos Naturais Renováveis (IBAMA), do Instituto Estadual de Florestas (IEF), da Fundação Estadual do Meio Ambiente (FEAM) e da Companhia de Saneamento de Minas Gerais (COPASA) (Figura 2).

\begin{tabular}{|c|c|c|c|c|c|c|}
\hline & $\begin{array}{l}\text { JURISDIÇÃO } \\
\text { CATEGORIA }\end{array}$ & IBAMA & FEAM & IEF & COPASA & TOTAL \\
\hline \multirow{7}{*}{$\begin{array}{l}\text { USO } \\
\text { INDIRETO }\end{array}$} & PARQUE & 05 & & 08 & & 13 \\
\hline & ESTAÇÃO ECOLÓGICA & 01 & 01 & 06 & & 08 \\
\hline & RESERVA BIOLÓGICA & & & 01 & & 01 \\
\hline & \begin{tabular}{|l|} 
RESERVA PARTICULAR \\
DO PATRIM. NATURAL \\
\end{tabular} & 15 & & & & 15 \\
\hline & ÁREA PROT. ESPECIAL & & 02 & & & 02 \\
\hline & $\begin{array}{c}\text { ÁREA PRESERVAÇÃO } \\
\text { PERMANENTE }\end{array}$ & & 02 & & & 02 \\
\hline & SUBTOTAL & 21 & 06 & 15 & & 41 \\
\hline \multirow{3}{*}{ USO DIRETO } & FLORESTA NACIONAL & 01 & & & & 01 \\
\hline & $\begin{array}{c}\text { ÁREAS PROTEÇÃO } \\
\text { AMBIENTAL } \\
\end{array}$ & 04 & 05 & & & 09 \\
\hline & SUBTOTAL & 05 & 05 & & & 10 \\
\hline \multirow[t]{2}{*}{ M ANANC. } & $\begin{array}{c}\text { ÁREAS PROTEÇÃO } \\
\text { ESPECIAL }\end{array}$ & & & & 16 & 16 \\
\hline & SUBTOTAL & & & & 16 & 16 \\
\hline \multicolumn{2}{|r|}{ TOTAL } & 26 & 10 & 15 & 16 & 67 \\
\hline
\end{tabular}

Tabela 1: Síntese das áreas protegidas em Minas Gerais - número de unidades (Fonte: Cadastro de Unidades de Conservação. FEAM, dezembro/1995).

Table 1: Table of protected areas in Minas Gerais - number of units (Source: FEAM. Cadastro de Unidades de Conservação, dec. 1995).

\begin{tabular}{|c|c|c|c|c|c|c|}
\hline & $\begin{array}{l}\text { JURISDIÇÃO } \\
\text { CATEGORIA }\end{array}$ & IBAMA & FEAM & IEF & COPASA & TOTAL \\
\hline \multirow{7}{*}{$\begin{array}{l}\text { USO } \\
\text { INDIRETO }\end{array}$} & PARQUE & 207.363 & & 90.714 & & 298.077 \\
\hline & $\begin{array}{l}\text { ESTAÇÃO } \\
\text { ECOLÓGICA }\end{array}$ & 1.090 & 337 & 6.547 & & 7.974 \\
\hline & $\begin{array}{l}\text { RESERVA } \\
\text { BIOLÓGICA }\end{array}$ & & & 6.514 & & 6.514 \\
\hline & $\begin{array}{c}\text { RESERVA PARTIC. } \\
\text { DO PATRIM. } \\
\text { NATURAL }\end{array}$ & 20.258 & & & & 20.258 \\
\hline & $\begin{array}{c}\text { ÁREA DE PROTEÇÃO } \\
\text { ESPECIAL }\end{array}$ & & 6.075 & & & 6.075 \\
\hline & $\begin{array}{c}\text { ÁREA } \\
\text { PRESERVAÇÃO } \\
\text { PERMANENTE }\end{array}$ & & 712 & & & 712 \\
\hline & SUBTOTAL & 228.711 & 7.124 & 103.775 & & 339.610 \\
\hline \multirow{3}{*}{ USO DIRETO } & $\begin{array}{l}\text { FLORESTA } \\
\text { NACIONAL }\end{array}$ & 335 & & & & 335 \\
\hline & $\begin{array}{c}\text { ÁREA DE PROTEÇÃO } \\
\text { AMBIENTAL }\end{array}$ & 543.522 * & 170.550 * & & & 714.072 * \\
\hline & SUBTOTAL & $543.857^{*}$ & 170.550 * & & & 714.404 \\
\hline \multirow{2}{*}{$\begin{array}{l}\text { MANAN- } \\
\text { CIAIS }\end{array}$} & $\begin{array}{c}\text { ÁREAS PROTEÇÃO } \\
\text { ESPECIAL }\end{array}$ & & & & 183.567 & 183.567 \\
\hline & SUBTOTAL & & & & 183.567 & 183.567 \\
\hline \multicolumn{2}{|r|}{ TOTAL } & 772.568 & 177.674 & 103.775 & 183.567 & 1.237 .584 \\
\hline
\end{tabular}

Tabela 2: Síntese das áreas protegidas em Minas Gerais dimensão em hectares (Fonte:

Cadastro de Unidades de Conservação. FEAM, dezembro/ 1995). (*) Área total, retiradas as unidades de uso indireto inseridas.

Table 2: Table of protected areas in

Minas Gerais - surface in ha (Source: FEAM. Cadastro de

Unidades de Conservação, december 1995). (*) Reports total area discounting the units of indirect use.

6 - Citam-se as propostas dos planos de sistema de unidades de conservação do Brasil, 1979, 1982, 1989 e 1992. 


\begin{tabular}{|c|c|c|c|c|c|c|}
\hline $\begin{array}{l}\text { DÉCADAS } \\
\text { CATEGORIA }\end{array}$ & 30 & 40 & 60 & 70 & 80 & 90 \\
\hline $\begin{array}{c}\text { 1. Parque } \\
\text { Nacional } \\
\text { (Estadual/ } \\
\text { Municipal) }\end{array}$ & $\left|\begin{array}{c}\text { Decreto } n=23.793 \mathrm{de} \\
23.01 .34\end{array}\right|$ & $\begin{array}{c}\text { Decreto Legislativo } \\
\mathrm{n}^{\circ} 3 \text { de } 13.02 .48\end{array}$ & $\begin{array}{l}\text { Leino } 4.771 \mathrm{de} \\
\quad 15.09 .65\end{array}$ & \begin{tabular}{|c|} 
Decreto n$^{\circ} 84.017 \mathrm{de}$ \\
21.09 .79
\end{tabular} & \begin{tabular}{|c|} 
Resolução CONAMA \\
$n^{\circ} 011$ de 03.12 .87
\end{tabular} & \\
\hline $\begin{array}{l}\text { 2. Floresta } \\
\text { Nacional } \\
\text { (Estadual } \\
\text { Municipal) }\end{array}$ & $\mid \begin{array}{c}\text { Decreto } n^{0} 23.793 \mathrm{de} \\
23.01 .34\end{array}$ & & $\begin{array}{c}\text { Lei no } 4.771 \mathrm{de} \\
15.09 .65\end{array}$ & & $\begin{array}{c}\text { Resolução CONAMA } \\
\mathrm{n} ; 011 \text { de } 03.12 .87\end{array}$ & \\
\hline $\begin{array}{l}\text { 3. Floresta } \\
\text { Protetora }\end{array}$ & \begin{tabular}{|c|} 
Decreto $n^{0}-23.793 \mathrm{de}$ \\
$23.01 .34(6)$
\end{tabular} & & & & & \\
\hline $\begin{array}{l}\text { 4. Reserva } \\
\text { Nacional }\end{array}$ & & $\begin{array}{c}\text { Decreto Legislativo } \\
\text { o } 3 \text { de } 13.02 .48\end{array}$ & & & & \\
\hline $\begin{array}{l}\text { 5. Monumento } \\
\text { Nac. Natural }\end{array}$ & & $\begin{array}{c}\text { Decreto Legislativo } \\
\text { № } 3 \text { de 13.02.48 }\end{array}$ & & & \begin{tabular}{|c|} 
Resolução CONAMA \\
no 011 de 03.12.87
\end{tabular} & \begin{tabular}{|c|} 
Decreto 58.054 de \\
23.03 .95
\end{tabular} \\
\hline $\begin{array}{l}\text { 6. Reserva de } \\
\text { Região Virgem }\end{array}$ & & $\begin{array}{c}\text { Decreto Legislativo } \\
\text { no } 3 \text { de } 13.02 .48\end{array}$ & & & & \\
\hline $\begin{array}{l}\text { 7. Reserva } \\
\text { Biológica }\end{array}$ & & & $\begin{array}{c}\text { Lein } 0 \text { 4.771 de } \\
15.09 .65 ; \text { Lei } n^{0} \\
5.197 \text { de } 03.01 .67\end{array}$ & & $\begin{array}{c}\text { Resolução CONAMA } \\
\text { no } 011 \text { de 03.12.87 }\end{array}$ & \\
\hline $\begin{array}{l}\text { 8. Parque de } \\
\text { Caça }\end{array}$ & & & $\begin{array}{c}\text { Lein으.197 de } \\
03.01 .67\end{array}$ & & & \\
\hline $\begin{array}{l}\text { 9. Área Especial } \\
\text { de Interesse } \\
\text { Turístico }\end{array}$ & & & & $\begin{array}{l}\text { Leino } 6.513 \text { de } \\
20.12 .77\end{array}$ & & \\
\hline $\begin{array}{l}\text { 10. Estações } \\
\text { Ecológicas }\end{array}$ & & & & & \begin{tabular}{|c|} 
Lei no 6.902 de \\
27.04 .81 Lei $n^{\circ}$ \\
6.938 de 3.08.81 \\
Resolução CONAMA \\
004 de 18.09.85 \\
Resolução CONAMA \\
no 011 de 03.12.87 \\
\end{tabular} & \begin{tabular}{|l} 
Decreto $\mathrm{n}-99.274$ de \\
06.06 .90 \\
\end{tabular} \\
\hline $\begin{array}{l}\text { 11. Áreas de } \\
\text { Proteção } \\
\text { Ambiental }\end{array}$ & & & & & \begin{tabular}{|c|} 
Lei no 6.902 de \\
27.04 .81 Lei no \\
6.938 de 31.08.81. \\
Resolução CONAMA \\
oㅡ 011 de 03.12.87. \\
Resolução CONAMA \\
no 10 de 4.12.88 \\
\end{tabular} & $\begin{array}{l}\text { Decreto no } 99.274 \\
\text { de } 06.06 .90 \text { Lei no } \\
6.938 \text { de } 31.08 .81\end{array}$ \\
\hline $\begin{array}{l}\text { 12. Reservas } \\
\text { Ecológicas }\end{array}$ & & & & & 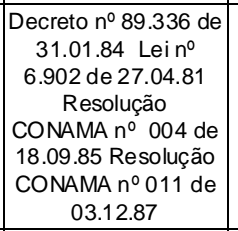 & \\
\hline $\begin{array}{l}\text { 13. Áreas de } \\
\text { Relev. Interesse } \\
\text { Ecológico }\end{array}$ & & & & & \begin{tabular}{|c|} 
Lei no 6.938 de \\
31.08.81 Decreto $\mathrm{n}^{\mathrm{0}}$ \\
89.336 de 31.01 .84 \\
\end{tabular} & \\
\hline $\begin{array}{l}\text { 14. Reservas } \\
\text { Extrativistas }\end{array}$ & & & & & & \begin{tabular}{|c|} 
Decreto n$^{\circ} 98.897 \mathrm{de}$ \\
30.01 .90
\end{tabular} \\
\hline $\begin{array}{l}\text { 15. Reservas } \\
\text { Particulares do } \\
\text { Patrimônio } \\
\text { Natural }\end{array}$ & & & & & & $\begin{array}{c}\text { Decreto } n^{0} 98.914 \\
\text { de } 31.01 .90\end{array}$ \\
\hline
\end{tabular}

Quadro 1: Legislação que estabelece categorias de manejo de Unidades de Conservação em nível federal.

Chart 1: Federal legislation establishing administrative categories of federal conservation units..

\begin{tabular}{|l|c|c|c|c|c|c|c|c|}
\hline \multicolumn{1}{|c|}{ DÉCADA DE CRIAÇÃO } & 20 & 30 & 40 & 50 & 60 & 70 & 80 & 90 \\
CATEGORIA & & & & & & & & \\
\hline Parque & & 1 & 1 & & 2 & 4 & 2 & 3 \\
\hline Estação Ecológica & & & & & & 5 & 1 & 2 \\
\hline $\begin{array}{l}\text { Reserva Biológica } \\
\text { Reserva Particular do Patrimônio } \\
\text { Natural }\end{array}$ & & & & & & 1 & & \\
\hline Área de Proteção Especial & & & & & & & 16 & 2 \\
\hline Área de Preservação Permanente & & & & & & & 2 & \\
\hline Floresta Nacional & & & & & 1 & & & \\
\hline Área de Proteção Ambiental & & & & & & & 6 & 3 \\
\hline Área Indígena & 1 & & & & & & 1 & 2 \\
\hline TOTAL & 1 & 1 & 1 & 0 & 3 & 10 & 28 & 27 \\
\hline
\end{tabular}

Quadro 2: Época de criação de Unidades de Conservação/Áreas Indígenas em Minas Gerais (Fonte: Legislação específica até dezembro de 1995). Chart 2: Periods of criation of conservation units and native reserves in Minas Gerais.

(Source: specific legislation till december 1995). 


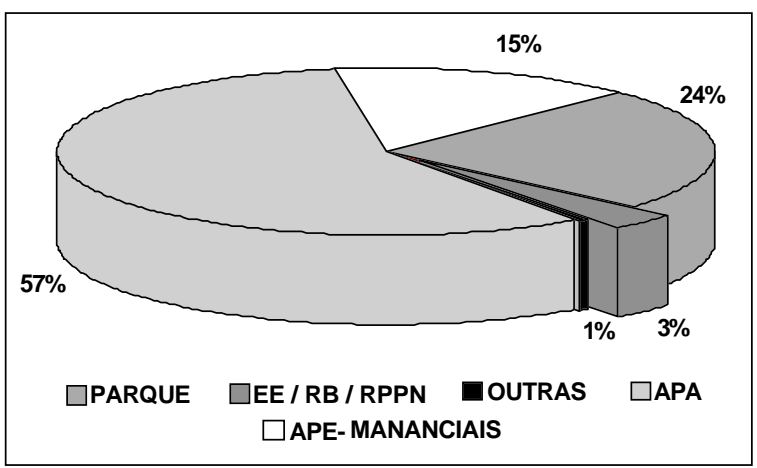

Figura 1: Superficie protegida por categoria de manejo (Fonte: FEAM. Cadastro de Unidades de Conservação de Minas Gerais, dezembro de 1995).

Figure 1: Protected surface individualized by administrative (Source: FEAM. Cadastro de Unidades de Conservação, december 1995).

O panorama das unidades de conservação existentes no Estado acompanha a situação brasileira, que apresenta-se "relativamente confusa quanto ao conjunto de categorias de manejo conceitual e legalmente instituídas (...). Tanto existem categorias que, por profunda semelhança de objetivos, se eqüivalem, como categorias sem definição clara de objetivos de manejo. Também categorias de manejo fundamentais ainda não foram instituídas, ao passo que outras, já instituídas legalmente há vários anos, não tiveram uma única unidade criada" (Milano 1995).

Pode-se citar, por exemplo, Reservas Biológicas e Estações Ecológicas como categorias que se sobrepõem em seus objetivos de manejo. As áreas declaradas como Áreas de Preservação Permanente são remetidas, pela legislação, à denominação de Reserva Ecológica. Esta, por sua vez, assemelha-se em seus objetivos aos definidos para Reservas Biológicas e Estações Ecológicas. Milano (1995) afirma ainda que "alguns instrumentos legais que instituem restrições ao uso do solo e à ocupação territorial têm sido confundidos e considerados como Unidades de Conservação, por sua semelhança com Áreas de Proteção Ambiental". Em Minas Gerais, isto ocorre com as Áreas de Proteção Especial (APE), criadas com base na Lei Federal 6.766 de 19.12.79 que regulamenta o uso e parcelamento do solo urbano, que estabelece áreas para a proteção de mananciais, patrimônio cultural, histórico, paisagístico e arqueológico. No Estado, as APE destinam-se, principalmente, à proteção de mananciais.

Remetendo-se ao discutido por Milano (1995), podese ainda citar o objetivo de manejo "proteção de sítios abióticos" como um dos objetivos não contemplados de forma prioritária pelas categorias de manejo adotadas no Estado, apesar de sua adequação ao patrimônio natural mineiro. Este é o objetivo primário da categoria Monumento Natural, ainda não utilizada no âmbito estadual. Esta categoria aguarda regulamentação legal.

Os objetivos de manejo alcançados em Minas Gerais

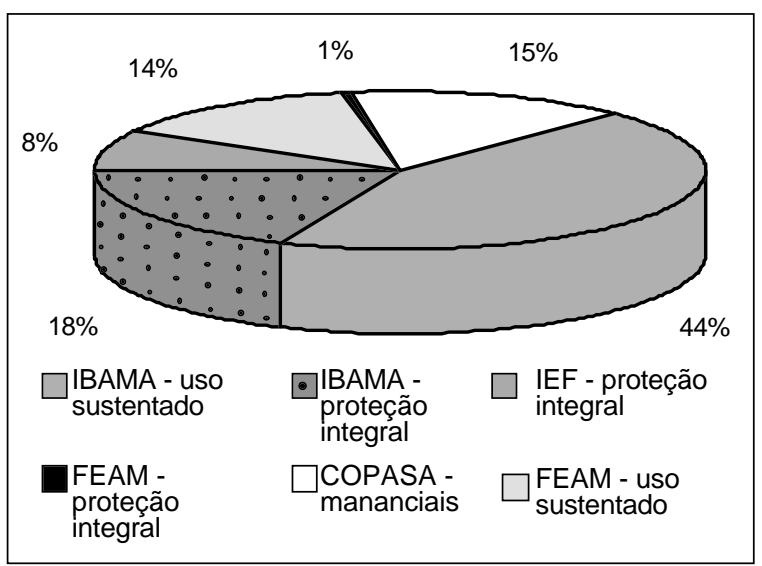

Figura 2: Superfície protegida por jurisdição.

Figure 2: Protected surface individualized through jurisdiction.

relacionam-se a um número restrito de categorias, conforme descrito a seguir.

\section{Estações Ecológicas e Reservas Biológicas}

Minas conta com uma Estação Ecológica sob jurisdição do IBAMA (1.090 ha ou 0,08 \% do solo protegido no Estado), uma sob jurisdição da FEAM (337 ha ou $0,03 \%$ ) e 06 (seis) do IEF (6.547 ha ou $0,5 \%$ ) (Quadros 3 e 4). O Estado possui uma Reserva Biológica, com área de 6.514 ha, que eqüivalem a $0,52 \%$ do território protegido, sob jurisdição do IEF (Quadro 5).

Estas categorias de manejo se destinam à proteção de áreas que possuem espécies ou ecossistemas de relevante valor científico, sendo necessário que os processos ecológicos prossigam sem interferência humana direta. Seu tamanho é determinado, em cada caso, pelas finalidades específicas às quais a unidade se destina e de acordo com as características do ecossistema a proteger (Milano 1995).

As Estações Ecológicas e Reservas Biológicas possuem objetivos de manejo idênticos, ou seja, preservar a diversidade biológica e os ecossistemas em estado de evolução livre, propiciar a obtenção de conhecimentos mediante pesquisas de caráter biológico ou ecológico, proteger espécies raras, endêmicas, vulneráveis ou em perigo de extinção, contribuir para o monitoramento ambiental fornecendo parâmetros relativos à áreas pouco afetadas por ações antrópicas (Milano 1995).

Até o momento, a legislação brasileira diferencia as duas categorias, permitindo até $10 \%$ de alteração antrópica nas Estações Ecológicas para fins de pesquisa científica ${ }^{7}$. O projeto de Lei Federal (substitutivo) 2892/92 prevê a unificação dessas duas categorias de manejo, reduzindo a área de alteração a $3 \%$ e limitando ao máximo de 1.500 ha. A propriedade da área é do poder público. 


\begin{tabular}{|c|c|c|c|c|}
\hline NOME & MUNICÍPIO & $\begin{array}{c}\text { LEGISLAÇÃO } \\
\text { DE CRIAÇÃO }\end{array}$ & $\begin{array}{c}\text { ÁREA } \\
\text { (ha) }\end{array}$ & JURISDIÇÃO \\
\hline $\begin{array}{c}\text { ESTAÇÃO } \\
\text { ECOLÓGICA DE } \\
\text { PIRAPITINGA }\end{array}$ & Morada Nova de Minas & $\begin{array}{c}\text { Decreto } n^{0} 94.656, \\
\text { de } 20.07 .87\end{array}$ & 1.090 & IBAMA \\
\hline
\end{tabular}

Quadro 3: Estações ecológicas federais (Fonte: legislação específica até dezembro de 1995).

Chart 3: Federal ecological stations (Source: specific legislation till december 1995).

\begin{tabular}{|c|c|c|c|c|}
\hline NOME & MUNICÍPIO & LEGISLAÇÃO DE CRIAÇÃO & $\begin{array}{l}\text { ÁREA } \\
\text { (ha) }\end{array}$ & JURISDIÇÃO \\
\hline $\begin{array}{c}\text { ESTAÇÃO ECOLÓGICA DE } \\
\text { CORUMBÁ (*) }\end{array}$ & Arcos & Decreto $n^{0} 16.580$, de 23.09 .74 & 304 & IEF \\
\hline $\begin{array}{l}\text { ESTAÇÃO ECOLÓGICA MAR } \\
\text { DE ESPANHA }\left({ }^{*}\right)\end{array}$ & Mar de Espanha & $\begin{array}{c}\text { Decreto } \text { no }^{\circ} 16.580 \text {, de } 23.09 .74 \text {, } \\
\text { Decreto } \text { no }^{-} 36.069 \text {, de 27.09.94, Lei } \\
\text { no } 11.731 \text {, de } 30.12 .94\end{array}$ & 187 & IEF \\
\hline $\begin{array}{c}\text { ESTAÇÃO ECOLÓGICA MATA } \\
\text { DOS AUSENTES }\left({ }^{*}\right)\end{array}$ & $\begin{array}{l}\text { Senador Modestino } \\
\text { Gonçalves }\end{array}$ & $\begin{array}{c}\text { Decreto } \mathrm{n}^{\circ} 16.580 \text {, de } 23.09 .74 \text {, } \\
\text { Decreto } \mathrm{n}^{\mathrm{0}} 36.584 \text {, de } 28.12 .94 \text {, Lei } \\
\text { no } 11.731 \text {, de } 30.12 .94\end{array}$ & 490 & IEF \\
\hline $\begin{array}{c}\text { ESTAÇÃO ECOLÓGICA DE } \\
\text { ACAUÃ (*) }\end{array}$ & $\begin{array}{l}\text { Turmalina, Leme do } \\
\text { Prado }\end{array}$ & $\begin{array}{c}\text { Decreto } \mathrm{n}^{\circ} 16.580 \text {, de } 23.09 .74 \text {, } \\
\text { Decreto } \mathrm{n}^{\mathrm{0}} 36.584 \text {, de } 28.12 .94 \text {, Lei } \\
\mathrm{n}^{\circ} 11.731 \text {, de } 30.12 .94\end{array}$ & 5.196 & IEF \\
\hline $\begin{array}{l}\text { ESTAÇÃO ECOLÓGICA DO } \\
\text { TRIPUÍ }\left({ }^{* *}\right)\end{array}$ & Ouro Preto & $\begin{array}{l}\text { Decreto no } 19.157, \text { de } 24.04 .78, \\
\text { Decreto no } 21.340 \text {, de } 04.06 .81\end{array}$ & 337 & COPAM/FEAM \\
\hline $\begin{array}{c}\text { ESTAÇÃO ECOLÓGICA DE } \\
\text { ÁGUA LIMPA }\end{array}$ & Cataguazes & $\begin{array}{c}\text { Decreto } \mathrm{n}^{\circ} 36.072 \text {, de } 27.09 .94 \text {, Lei } \\
\text { no } 11.731 \text { de } 30.12 .94 \\
\end{array}$ & 71 & IEF \\
\hline $\begin{array}{c}\text { ESTAÇÃO ECOLÓGICA DE } \\
\text { FECHOS }\end{array}$ & Nova Lima & Decreto $\mathrm{n}^{\circ} 36.073$, de 27.09 .94 & 603 & IEF/COPASA \\
\hline
\end{tabular}

Quadro4: Estações ecológicas estaduais (Fonte: legislação específica até dezembro/95).

(*) Reenquadrada de Reserva Biologica para Estação Ecológica.

(**) Reenquadrada de Estação Biológica para Estação Ecológica.

Chart 4: State ecological stations (Source: specific legislation till december 1995).

(*) Changed from Biological Reserve to Ecological Station

(**) Changed from Biological Station to Ecological Station.

\begin{tabular}{|c|c|c|c|c|}
\hline NOME & MUNICÍPIO & $\begin{array}{l}\text { LEGISLAÇÃO } \\
\text { DE CRIAÇÃO }\end{array}$ & $\begin{array}{c}\text { ÁREA } \\
\text { (ha) }\end{array}$ & JURISDIÇÃO \\
\hline $\begin{array}{l}\text { RESERVA } \\
\text { BIOLÓGICA } \\
\text { DO JAIIBA }\left({ }^{*}\right)\end{array}$ & Matias Cardoso & $\begin{array}{c}\text { Lei } n^{\circ} 6.126 \text {, de } \\
04.07 .77 \text {, Lei } n^{\circ} \\
11.731 \text {, de } \\
30.12 .94\end{array}$ & 6.210 & IEF \\
\hline
\end{tabular}

Quadro 5: Reservas biológicas estaduais (Fonte: legislação específica até dezembro de 1995).

(*) Reenquadrada de Parque Florestal para Reserva Biológica.

Chart 5: State Biological Reserves (Source: specific legislation till december 1995).

(*) Changed from Forest Park to Biological Reserve.

\section{Parques}

Os parques nacionais cobrem 207.363 ha no Estado de Minas Gerais e representam 16,76\% do total de áreas protegidas (Quadro 6). Os parques estaduais perfazem 90.714 ha, ou 7,33\% das áreas protegidas (Quadro 7).

A categoria de manejo Parque se adequa à proteção de áreas representativas de ecossistemas naturais que possuam potencial para o desenvolvimento de atividades turísticas e recreativas. Nos parques deve ser possível compatibilizar as atividades de lazer e educação ambiental com a preservação integral dos recursos naturais. Por isto, requerem, normalmente, grandes extensões de ambientes naturais.
Estas áreas serão divididas, de acordo com o zoneamento proposto, em parcelas com usos diferenciados, algumas propícias à visitação e à educação ambiental e outras à estudos científicos e à manutenção dos processos naturais.

Os objetivos de manejo prioritários de um parque são preservação, desenvolvimento de pesquisas científicas, recreação e educação ambiental. A propriedade da área é do poder público.

\section{Reservas Particulares do Patrimônio Natural}

A figura jurídica da Reserva Particular do Patrimônio (RPPN) surgiu para possibilitar a preservação de áreas naturais sob responsabilidade do próprio proprietário. 


\begin{tabular}{|c|c|c|c|c|}
\hline NOME & MUNICíPIO & LEGISLAÇÃO DE CRIAÇÃO & $\begin{array}{l}\text { ÁREA } \\
\text { (ha) }\end{array}$ & JURISDIÇÃO \\
\hline $\begin{array}{c}\text { PARQUE NACIONAL DO } \\
\text { ITATIAIA }\end{array}$ & $\begin{array}{l}\text { MG - Itamonte, } \\
\text { Bocaina de Minas, } \\
\text { RJ - Resende }\end{array}$ & $\begin{array}{l}\text { Decreto } \mathrm{n}^{0} 1.713 \text {, de } 14.06 .37 \text {, } \\
\text { Decreto } \mathrm{n}^{0} 87.586 \text {, de } 20.09 .82\end{array}$ & $\begin{array}{c}30.000 \\
\text { (Área } \\
\text { em MG: } \\
15.463 \text { ) }\end{array}$ & IBAMA \\
\hline $\begin{array}{l}\text { PARQUE NACIONAL DO } \\
\text { CAPARAÓ }\end{array}$ & $\begin{array}{l}\text { MG - Caparaó, Espera } \\
\text { Feliz, Alto Jequitibá, } \\
\text { Alto Caparaó, } \\
\text { ES - Alegre, lúna, } \\
\text { Dores do Rio Preto, } \\
\text { Divino de São } \\
\text { Lourenço }\end{array}$ & Decreto $\mathrm{n}^{0} 50.646$, de 24.05 .61 & $\begin{array}{l}26.000 \\
\text { (Área } \\
\text { em MG: } \\
7.235 \text { ) }\end{array}$ & IBAMA \\
\hline $\begin{array}{l}\text { PARQUE NACIONAL DA } \\
\text { SERRA DA CANASTRA }\end{array}$ & $\begin{array}{l}\text { São Roque de Minas, } \\
\text { Sacramento e } \\
\text { Delfinópolis }\end{array}$ & Decreto $n^{0} 70.355$, de 03.04 .72 & 70.920 & IBAMA \\
\hline $\begin{array}{l}\text { PARQUE NACIONAL DA } \\
\text { SERRA DO CIPÓ }\end{array}$ & $\begin{array}{c}\text { Jaboticatubas, } \\
\text { Santana do Riacho, } \\
\text { Morro do Pilar e } \\
\text { Itambé do Mato Dentro }\end{array}$ & $\begin{array}{l}\text { Decreto } \mathrm{n} \text { 19.278, de 03.07.77, } \\
\text { Decreto } \mathrm{n}^{\mathrm{0}} 9.223 \text {, de 25.09.84 }\end{array}$ & 31.010 & IBAMA \\
\hline $\begin{array}{l}\text { PARQUE NACIONAL GRANDE } \\
\text { SERTÃO VEREDAS }\end{array}$ & $\begin{array}{l}\text { Formoso, Januária, } \\
\text { Arinos }\end{array}$ & Decreto no 97.658 , de 12.04 .89 & 82.735 & IBAMA \\
\hline
\end{tabular}

Quadro 6: Parques federais (Fonte: legislação específica até dezembro de 1995).

Chart 6: Federal Parks (Source: specific legislation till december 1995).

\begin{tabular}{|c|c|c|c|c|}
\hline $\begin{array}{c}\text { NOME } \\
\text { PARQUE ESTADUAL } \\
\text { DO RIO DOCE }\end{array}$ & $\begin{array}{l}\text { MUNICÍPIO } \\
\text { Timóteo, Marliéria, } \\
\text { Dionísio }\end{array}$ & $\begin{array}{l}\text { LEGISLAÇÃO DE CRIAÇÃO } \\
\text { Decreto no } 1.119 \text {, de } 14.07 .44 \text {, } \\
\text { Decreto no 5.831, de } 06.07 .60\end{array}$ & $\begin{array}{l}\text { ÁREA } \\
\text { (ha) } \\
35.970\end{array}$ & $\begin{array}{l}\text { JURISDIÇÃO } \\
\text { IEF }\end{array}$ \\
\hline $\begin{array}{l}\text { PARQUE ESTADUAL DO } \\
\text { ITACOLOMI }\end{array}$ & Ouro Preto e Mariana & Lei Estadual no 4.495, de 14.06.67 & 7.542 & IEF \\
\hline $\begin{array}{c}\text { PARQUE FLORESTAL } \\
\text { DO IBITIPOCA }\end{array}$ & $\begin{array}{c}\text { Lima Duarte e } \\
\text { Santa Rita do Ibitipoca }\end{array}$ & Lei $n^{\circ} 6.126$, de 04.07 .73 & 1.488 & IEF \\
\hline $\begin{array}{c}\text { PARQUE FLORESTAL } \\
\text { DA BALEIA }\end{array}$ & Belo Horizonte & Decreto $\mathrm{n}^{\circ} 26.162$, de 06.07 .88 & 102 & IEF \\
\hline $\begin{array}{l}\text { PARQUE ESTADUAL } \\
\text { DO RIO PRETO }\end{array}$ & $\begin{array}{l}\text { São Gonçalo } \\
\text { do Rio Preto }\end{array}$ & $\begin{array}{c}\text { Lei } n^{\circ} \text { 11.172, de 29.07.93, } \\
\text { Decreto no } 35.611 \text { de 02.06.94 }\end{array}$ & 10.755 & IEF \\
\hline $\begin{array}{l}\text { PARQUE ESTADUAL } \\
\text { DE NOVA BADEN }\left(^{*}\right)\end{array}$ & Lambari & $\begin{array}{l}\text { Decreto-Lei no } 16.580 \text {, de } 23.09 .74 \\
\quad \text { alterado Decreto no } 36.069 \text {, de } \\
\text { 27.09.94, Lei n } 11.731 \text {, de } 30.12 .94\end{array}$ & 214 & IEF \\
\hline $\begin{array}{c}\text { PARQUE ESTADUAL } \\
\text { DA SERRA DO ROLA-MOÇA }\end{array}$ & $\begin{array}{c}\text { Belo Horizonte, } \\
\text { Brumadinho, Ibirité e } \\
\text { Nova Lima }\end{array}$ & Decreto no 36.071 , de 27.09 .94 & 3.941 & IEF/COPASA \\
\hline $\begin{array}{c}\text { PARQUE ESTADUAL } \\
\text { VEREDAS DO PERUAÇU }\end{array}$ & $\begin{array}{c}\text { Januária, } \\
\text { Cônego Marinho }\end{array}$ & Decreto nㅇ 36.070 , de 27.09 .94 & 30.702 & IEF/COPASA \\
\hline
\end{tabular}

Quadro 7: Parques estaduais (Fonte: legislação específica até dezembro de 1995).

(*) Reenquadrada de Reserva Biológica para Parque.

Chart 7: State Parks (Source: specific legislation till december 1995).

(*) Changed from Biological Reserve to Park.

O Decreto Federal $\mathrm{n}^{\circ} 98.914$ de 30.01.90, permite ao IBAMA reconhecer como reservas permanentes, por interesse do proprietário, as áreas onde sejam identificados atributos naturais que justifiquem sua preservação.

Foram criadas, nestes quase 6 anos, 15 RPPN em Minas Gerais, cobrindo um total de 20.258 ha, 1,64\% da parcela protegida do Estado (Quadro 8).

A classificação de áreas de domínio privado como RPPN além de representar um incentivo fiscal, uma vez que as torna isentas do Imposto Territorial Rural - ITR, impede um possível processo desapropriatório para fins de reforma agrária, pois, de glebas "improdutivas" passam a ser consideradas unidades de conservação.
Os objetivos de manejo prioritários destas reservas são a preservação dos recursos naturais e o desenvolvimento de pesquisas. Naquelas que apresentam potencial turístico, quando da definição de seus limites, tem-se adotado a exclusão de parcelas de uso intensivo destinadas à este fim. Um exemplo disto é a RPPN do Caraça, de propriedade da Província Brasileira da Congregação da Missão.

\section{Florestas Nacionais}

Esta categoria se adequa a áreas cobertas por florestas manejáveis e produtivas, nativas ou plantadas em menor escala. Os objetivos de manejo prioritários da categoria são a exploração e manejo dos recursos 


\begin{tabular}{|c|c|c|c|c|}
\hline NOME & MUNICÍPIO & LEGISLAÇÃO DE CRIAÇÃO & $\begin{array}{l}\text { ÁREA } \\
\text { (ha) }\end{array}$ & PROPRIET. \\
\hline $\begin{array}{l}\text { RPPN FAZENDA } \\
\text { VEREDA GRANDE }\end{array}$ & Presidente Olegánio & Portania $n^{0} 643$, de 03.05 .90 & 2.995 & $\begin{array}{c}\text { FAZENDA } \\
\text { VEREDA } \\
\text { GRANDE S.A }\end{array}$ \\
\hline $\begin{array}{l}\text { RPPN FAZENDA } \\
\text { PEDRA BONITA }\end{array}$ & $\begin{array}{c}\text { São João } \\
\text { Nepomuceno }\end{array}$ & Portania no 044 , de 27.04 .92 & 33 & $\begin{array}{c}\text { ELMAR } \\
\text { BATISTA } \\
\text { MOREIRA }\end{array}$ \\
\hline $\begin{array}{l}\text { RPPN CLUBE DE CAÇA } \\
\text { E PESCA ITORORÓ }\end{array}$ & Uberlândia & Portania $n^{\circ} 084$, de 07.08 .92 & 127 & $\begin{array}{l}\text { CLUBE C.P } \\
\text { ITORORÓ DE } \\
\text { UBERLÂNDIA }\end{array}$ \\
\hline RPPN FAZENDA CAETANO & Paracatu & Portania no 147 , de 30.12 .92 & 1.421 & $\begin{array}{c}\text { ANTÔNIA } \\
\text { ULHOA }\end{array}$ \\
\hline $\begin{array}{l}\text { RPPN FAZENDA CAETANO } \\
\text { LOCALID. SANTO } \\
\text { AGOSTINHO }\end{array}$ & Paracatu & Portania no 146 , de 30.12 .92 & 1.184 & $\begin{array}{c}\text { MARIA } \\
\text { ANGÉLICA } \\
\text { ULHOA DAN, } \\
\text { RENATO DAN }\end{array}$ \\
\hline RPPN BELGO MINEIRA & João Monlevade & Portaria $n^{0} 17$, de 19.02 .93 & 519 & $\begin{array}{l}\text { CIA. SIDER. } \\
\text { BELGO } \\
\text { MINEIRA } \\
\end{array}$ \\
\hline $\begin{array}{l}\text { RPPN FAZENDA } \\
\text { CATINGUEIRO I }\end{array}$ & Lagoa da Prata & Portania no 102 , de 29.09 .93 & 50 & $\begin{array}{c}\text { ALDA } \\
\text { BERNARDES } \\
\text { DE CASTRO } \\
\end{array}$ \\
\hline $\begin{array}{l}\text { RPPN FAZENDA } \\
\text { CATINGUEIRO ॥ }\end{array}$ & Lagoa da Prata & Portania no 103 , de 29.09 .93 & 39 & $\begin{array}{l}\text { ALBERTINA B. } \\
\text { DE CASTRO }\end{array}$ \\
\hline RPPN CARAÇA & Santa Bárbara & Portaria $n^{0} 32$, de 30.03 .94 & 10.188 & $\begin{array}{c}\text { PROVÍNCIA } \\
\text { BRAS. CONG. } \\
\text { DA MISSÃO }\end{array}$ \\
\hline $\begin{array}{c}\text { RPPN SíTIO SÃO } \\
\text { DOMINGOS/AGARTHA }\end{array}$ & Espera Feliz & Portaria $n^{0} 54$, de 23.05 .94 & 2 & $\begin{array}{l}\text { RENATO J.I } \\
\text { MILHIOLO, } \\
\text { ANA MARIA } \\
\text { MILHIOLO }\end{array}$ \\
\hline RPPN FAZENDA MACEDÔNIA & Ipaba & Portania no 111, de 14.10.94 & 560 & CENIBRA \\
\hline $\begin{array}{l}\text { RPPN FAZENDA JOÃO } \\
\text { PEREIRA, POÇO FUNDO }\end{array}$ & Congonhas & Portaria $n^{\circ} 36$, de 02.06 .95 & 337 & $\begin{array}{l}\text { CIA. DE } \\
\text { MINERAÇÃO } \\
\text { SERRA DA } \\
\text { MOEDA }\end{array}$ \\
\hline $\begin{array}{c}\text { RPPN FAZENDA } \\
\text { ALTO DA BOA VISTA }\end{array}$ & Descoberto & Portaria $n^{\circ} 57$ de 17.08 .95 & 96 & $\begin{array}{l}\text { HELVÉCIO } \\
\text { RODRIGUES } \\
\text { PEREIRA } \\
\text { FILHO } \\
\end{array}$ \\
\hline RPPN FAZENDA SAMOINHO & lgaratinga & Portaria $n^{0}$ 59, de 22.08 .95 & 12 & $\begin{array}{l}\text { BIETER } \\
\text { ALTHOFF }\end{array}$ \\
\hline RPPN GALHEIROS & Perdizes & Portaria no 72 , de 06.09 .95 & 2.695 & CEMIG \\
\hline
\end{tabular}

Quadro 8: Reservas particulares do patrimônio natural (Fonte: legislação específica até dezembro de 1995).

Chart 8: Private reserves of natural patrimony (Source: specific legislation till december 1995).

de fauna e flora, desenvolvimento de culturas (animais e vegetais), desenvolvimento de pesquisas científicas ou tecnológicas e incentivo ao desenvolvimento regional, orientados pelo conceito do uso múltiplo e rendimento sustentado. Esta categoria pode proporcionar, também, oportunidades para recreação, educação ambiental, pesca, investigação e monitoramento. A propriedade do solo é pública (Milano 1995).

Existe apenas uma Floresta Nacional em Minas, com 335 ha, representando 0,03\% do território protegido (Quadro 9).

A Lei Florestal do Estado prevê a criação de Florestas Sociais com objetivos de manejo idênticos, porém de domínio privado, o que ainda não foi utilizado no Estado.

\section{Áreas de Proteção Ambiental}

Esta categoria se destina a promover o desenvolvimento sustentado em regiões que possuem características naturais e semi-naturais notáveis, em função de seus atributos bióticos, abióticos, culturais ou estéticos e, que comportem atividades econômicas compatíveis com a conservação desses recursos.

Este objetivo é alcançado através da supervisão do poder público com a definição do zoneamento ambiental, diretrizes de uso do solo e implantação de programas específicos de incentivo às modalidades de manejo existentes e implantação de atividades econômicas alternativas. As Áreas de Proteção Ambiental (APA) devem ser gerenciadas por conselhos, compostos de representantes dos diversos segmentos da sociedade que possuam interesses na região.

Seu principal papel é o de harmonizar o desenvolvimento sócio-econômico com as necessidades de conservação dos recursos naturais. São objetivos de manejo das APA conservar e melhorar as condições ecológicas locais, preservar paisagens e atributos naturais e culturais, fomentar o uso sustentado dos recursos naturais, manejar recursos de fauna e flora, proteger e melhorar a qualidade da água, manter regimes hídricos, propiciar pesquisas científicas relacionadas à conservação e atividades antrópicas, contribuir para o monitoramento ambiental, manter a 


\begin{tabular}{|c|c|c|c|c|}
\hline NOME & MUNICÍPIO & $\begin{array}{c}\text { LEGISLAÇÃO } \\
\text { DE CRIAÇÃO }\end{array}$ & $\begin{array}{c}\text { ÁREA } \\
\text { (ha) }\end{array}$ & JURISDIÇÃO \\
\hline $\begin{array}{c}\text { FLORESTA } \\
\text { NACIONAL } \\
\text { PASSA-QUATRO }\end{array}$ & Passa-Quatro & $\begin{array}{c}\text { Portaria } \mathrm{n}^{\circ} \text { 562, de } \\
25.10 .68, \text { do IBDF }\end{array}$ & 335 & IBAMA \\
\hline
\end{tabular}

Quadro 9: IBAMA - Floresta Nacional (Fonte: legislação específica até dezembro de 1995).

Chart 9:National Forest (IBAMA) (Source: specific legislation till december 1995).

população no local promovendo a melhoria de suas condições de vida e incentivar o desenvolvimento regional. As APA podem funcionar como áreas-piloto para a prática do ecodesenvolvimento e sua difusão. Mantém-se a propriedade particular do solo.

Existem nove APA em Minas Gerais, que perfazem 761.527 ha. Retirando deste total as dimensões de unidades de conservação de uso indireto inseridas nestas áreas teremos 714.072 ha definidos como APA, ou $57,69 \%$ do território protegido no Estado (Quadros 10 e 11).

Destaca-se o processo de revisão, em andamento, do decreto de criação da APA Sul-RMBH ,que prevê em seu Art. $5^{\circ}$ a não incidência sobre a área das restrições relativas à categoria APA até o seu zoneamento. $\mathrm{O}$ definido neste artigo tinha levado a sua exclusão do cadastro base para o cálculo do ICMS Ecológico, em dezembro de 1995.

Nos últimos meses foram criadas, por iniciativa do Poder Legislativo, mais 05 APA estaduais, sem que os instrumentos legais de criação definissem seus limites.
Estes instrumentos de lei representam, portanto, indicações de áreas a serem protegidas e não uma proteção efetiva (Quadro 12).

\section{Outras classes de proteção em Minas Gerais}

Existem 16 áreas delimitadas para proteção de mananciais em Minas Gerais, que eqüivalem a 183.567 ha ou $14,8 \%$ do total de áreas protegidas no Estado (Quadro 13). O mecanismo legal utilizado foi a criação de Áreas de Proteção Especial (APE), previstas na Lei de Parcelamento do Solo Urbano (Lei Federal 6.766 de 19/12/79). Em Minas, estão sob jurisdição da Companhia de Saneamento de Minas Gerais - COPASA. Normalmente são delimitadas sub-bacias à montante de pontos de captação, nas quais, em alguns casos, parcelas são adquiridas para instalação de Estações de Captação de Água. No restante o parcelamento do solo está sujeito ao licenciamento do órgão ambiental estadual.

É importante observar que a figura Área de Proteção Especial, definida pela lei de parcelamento do solo urbano representa um instrumento de controle do uso

\begin{tabular}{|c|c|c|c|c|}
\hline NOME & MUNICÍPIO & $\begin{array}{l}\text { LEGISLAÇÃO } \\
\text { DE CRIAÇÃOO }\end{array}$ & $\begin{array}{l}\text { ÁREA } \\
\text { (ha) }\end{array}$ & JURISDIÇÃO \\
\hline $\begin{array}{l}\text { ÁREA DE PROTEÇÃO } \\
\text { AMBIENTAL SERRA } \\
\text { DA MANTIQUEIRA }\left(^{*}\right)\end{array}$ & $\begin{array}{l}\text { MG -Bocaina de Minas, Aiuruoca, } \\
\text { Alagoa, Baependi, , Delfim Moreira, } \\
\text { Itanhandu, Itamonte, Liberdade, } \\
\text { Virgínia Marmelópolis, Passa-Quatro, } \\
\text { Passa-Vinte, Piranguçu, Pouso Alto, } \\
\text { Bom Jardim de Minas, Venceslau } \\
\text { Brás. SP-Cruzeiro, Queluz, Lavrinhas, } \\
\text { Campos do Jordão, Piquete, } \\
\text { Pindamonhangaba, Santo Antônio do } \\
\text { Pinhal. RJ - Resende. }\end{array}$ & $\begin{array}{l}\text { Decreto } \\
\text { ํo } 91.304 \text {, de } \\
\text { 03.06.85 }\end{array}$ & $\begin{array}{c}402.51 \\
\text { (Área MG: } \\
281.196)\end{array}$ & IBAMA \\
\hline $\begin{array}{l}\text { ÁREA DE PROTEÇÃO } \\
\text { AMBIENTAL } \\
\text { CAVERNAS DO } \\
\text { PERUAÇU }\left(^{* *}\right) \\
\end{array}$ & $\begin{array}{c}\text { Januária, Itacarambi, Cônego Marinho, } \\
\text { Bonito de Minas, São João das } \\
\text { Missões }\end{array}$ & $\begin{array}{l}\text { Decreto } \mathrm{n}^{\circ} \\
98.182 \text {, de } \\
26.09 .89\end{array}$ & 155.910 & IBAMA \\
\hline $\begin{array}{l}\text { ÁREA DE PROTEÇÃO } \\
\text { AMBIENTAL CARSTE } \\
\text { LAGOA SANTA }\end{array}$ & $\begin{array}{l}\text { Pedro Leopoldo, Lagoa Santa, } \\
\text { Matozinhos, Confins, Funilândia }\end{array}$ & $\begin{array}{l}\text { Decreto } \mathrm{n}^{\circ} \\
98.881, \text { de } \\
25.01 .90\end{array}$ & 38.091 & IBAMA \\
\hline $\begin{array}{l}\text { ÁREA DE PROTEÇÃO } \\
\text { AMBIENTAL MORRO } \\
\text { DA PEDREIRA }\end{array}$ & $\begin{array}{c}\text { Santana do Riacho, Morro do Pilar, } \\
\text { Itambé do Mato Dentro, Jaboticatubas, } \\
\text { Taquaraçu de Minas, Itabira, } \\
\text { Nova União }\end{array}$ & $\begin{array}{l}\text { Decreto } \mathrm{n}^{\circ} \\
98.891 \text {, de } \\
26.01 .90\end{array}$ & 99.362 & IBAMA \\
\hline
\end{tabular}

Quadro 10: Áreas de proteção ambiental federais (Fonte: legislação específica até dezembro de 1995). (*) APA Mantiqueira cobre 280.861 ha de uso direto, uma vez retiradas a área da Floresta Nacional de Passa Quatro. (**) A APA Cavernas do Peruaçu cobre 125.208 ha de uso direto, uma vez retirado o Parque Estadual Veredas do Peruaçu.

Chart 10: Federal areas of environmental protection - APA (Source: specific legislation till december 1995).

(*) APA Mantiqueira covers 280,861 ha of direct use, excluding the area of the Passa Quatro National Forest. (**) The APA Cavernas do Peruaçu covers 125,280 ha of direct use, excluding the Veredas do Peruaçu State Park. 


\begin{tabular}{|c|c|c|c|c|}
\hline NOME & MUNICÍPIO & $\begin{array}{l}\text { LEGISLAÇÃO } \\
\text { DE CRIAÇÃO }\end{array}$ & $\begin{array}{l}\text { ÁREA } \\
\text { (ha) }\end{array}$ & JURISDIÇÃO \\
\hline $\begin{array}{c}\text { ÁREA DE } \\
\text { PROTEÇÃO } \\
\text { AMBIENTAL SEMINÁRIO } \\
\text { MENOR DE MARIANA }\end{array}$ & Mariana & $\begin{array}{l}\text { Decreto } \mathrm{n}^{0} \\
23.564, \text { de } \\
11.05 .84\end{array}$ & 350 & COPAM/FEAM \\
\hline $\begin{array}{l}\text { ÁREA DE PROT. AMBIENTAL } \\
\text { GRUTA REI DO MATO }\end{array}$ & Sete Lagoas & $\begin{array}{c}\text { Decreto } n^{\circ} 8.670 \\
\text { de } 27.09 .84\end{array}$ & 160 & COPAM/FEAM \\
\hline $\begin{array}{c}\text { ÁREA DE PROT. AMBIENTAL } \\
\text { CACHOEIRA DAS } \\
\text { ANDORINHAS }\end{array}$ & Ouro Preto & $\begin{array}{c}\text { Decreto } \mathrm{n}^{\circ} \\
30.264, \text { de } \\
16.10 .89\end{array}$ & 18.700 & COPAM/FEAM \\
\hline $\begin{array}{l}\text { ÁREA DE PROT. AMBIENTAL } \\
\text { SERRA SÃO JOSÉ }\left(^{*}\right)\end{array}$ & $\begin{array}{l}\text { Tiradentes, Prados, Coronel } \\
\text { Xavier Chaves, São João Del } \\
\text { Rei, Santa Cruz de Minas }\end{array}$ & \begin{tabular}{|c|} 
Decreto $\mathrm{n}^{\circ}$ \\
21.308, de \\
19.05.81. Decreto \\
$\mathrm{n}^{\circ}$ 30.934, de \\
16.02 .90
\end{tabular} & 4.758 & COPAM/FEAM \\
\hline $\begin{array}{l}\text { ÁREA DE PROTEÇÃO } \\
\left.\text { AMBIENTAL SUL RMBH }{ }^{* *}\right)\end{array}$ & $\begin{array}{l}\text { Belo Horizonte, Brumadinho, } \\
\text { Caeté, Ibirité, Itabirito, Nova } \\
\text { Lima, Rio Acima, Santa } \\
\text { Bárbara, Raposos, Mário } \\
\text { Campos, Sarzedo }\end{array}$ & $\begin{array}{l}\text { Decreto } \mathrm{n}^{\circ} \\
35.624, \text { de } \\
08.06 .94\end{array}$ & 163.000 & COPAM/FEAM \\
\hline
\end{tabular}

Quadro 11: Áreas de proteção ambiental estaduais (Fonte: legislação específica até dezembro de 1995).

(*) Reenquadrada de APE para APA.(**) A APA Sul RMBH cobre 146.582 ha de uso direto, uma vez retiradas as interseções com as unidades de conservação de uso indireto nela inseridas: Parque Serra Rola-Moça, Estação Ecológica de Fechos, Áreas de Proteção Especial Catarina, Mutuca, Taboão, Barreiro, Fechos, Moça e Bálsamo e RPPN Caraça.

Chart 11: State areas of environmental protection (Source: specific legislation till december 1995).

(*) Changed from area of special protection to area of environmental protection. (**) The area of environmental protection South - Metropolitan Region of Belo Horizonte (APA Sul RMBH) covers 146,582 ha of direct use, excluding overlaps with convervation units of in direct use: Serra Rola Moça Park, Ecological Station of Fechos, Áreas of Special

Protection of Catarina, Mutuca, Taboão, Barreiro, Fechos, Moça and Bálsamo, as well as RPPN Caraça.

\begin{tabular}{|c|c|c|c|c|}
\hline NOME & MUNICÍPIO & $\begin{array}{l}\text { LEGISLAÇÃO DE } \\
\text { CRIAÇÃO }\end{array}$ & $\begin{array}{l}\text { ÁREA } \\
\text { (ha) }\end{array}$ & JURISDIÇÃO \\
\hline RB COLÔNIA 31 DE MARÇO & Felixlândia & $\begin{array}{c}\text { Decreto-Lei no } 16.580 \\
\text { de } 23.09 .74\end{array}$ & 5.033 & IEF \\
\hline $\begin{array}{c}\text { RB DE SÃO SEBASTIÃO } \\
\text { PARAÍSO }\end{array}$ & São Sebastião do Paraíso & $\begin{array}{c}\text { Decreto-Lei no } 16.580 \\
\text { de } 23.09 .74\end{array}$ & 248 & IEF \\
\hline RB CARMO DA MATA & Carmo da Mata & $\begin{array}{c}\text { Decreto-Lei } n^{\circ} 16.580 \\
\text { de } 23.09 .74\end{array}$ & 86 & IEF \\
\hline RB FAZENDA SÃO MATEUS & Ponte Nova & $\begin{array}{c}\text { Decreto-Lei } n^{\circ} 16.580 \\
\text { de } 23.09 .74\end{array}$ & 377 & IEF \\
\hline RB FAZENDA DA LAJINHA & Leopoldina & $\begin{array}{c}\text { Decreto-Lei } n^{\circ} 16.580 \\
\text { de } 23.09 .74\end{array}$ & 68 & IEF \\
\hline RB SANTA RITA & Prudente de Morais & $\begin{array}{c}\text { Decreto } \mathrm{n}^{\circ}-16.580 \text {, de } \\
23.09 .74\end{array}$ & 604 & IEF \\
\hline RB ESTADUAL DA CASCATA & Patos de Minas & $\begin{array}{c}\text { Decreto } \mathrm{n}^{\circ} 16.580 \text {, de } \\
23.09 .74 \\
\end{array}$ & 64 & IEF \\
\hline RB SETE LAGOAS & Sete Lagoas & $\begin{array}{c}\text { Decreto-Lei no } 16.580 \\
\text { de } 23.09 .74\end{array}$ & indefinida & IEF \\
\hline RB MATA DO JAMBREIRO & Nova Lima & $\begin{array}{c}\text { Lei } \mathrm{n}^{\circ} \text { 7.041, de } \\
19.07 .77\end{array}$ & 912 & IEF \\
\hline $\begin{array}{c}\text { PARQUE ESTADUAL MATA } \\
\text { DO KRAMBECK }\end{array}$ & Juiz de Fora & $\begin{array}{c}\text { Lei no } 10.943, \text { de } \\
27.11 .92, \text { Lei } n^{0} \\
11.336, \text { de } 21.12 .93\end{array}$ & 292 & IEF \\
\hline $\begin{array}{l}\text { APA LAGOAS MARGINAIS } \\
\text { DO RIO PIRACICABA }\end{array}$ & Indefinido & $\begin{array}{c}\text { Lei } \mathrm{n}^{\circ} \mathbf{1 1 . 8 3 1} \text {, de } \\
06.07 .95\end{array}$ & Indefinida & $\begin{array}{c}\text { Órgão } \\
\text { Estadual }\end{array}$ \\
\hline $\begin{array}{c}\text { APA LAGOAS MARGINAIS } \\
\text { DO RIO DOCE }\end{array}$ & Indefinido & 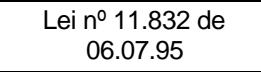 & Indefinida & $\begin{array}{l}\text { Órgão } \\
\text { Estadual }\end{array}$ \\
\hline $\begin{array}{l}\text { APA -ÁREAS DE INTERESSE } \\
\text { ECOLÓGICO BACIA DO RIO } \\
\text { PANDEIROS }\end{array}$ & Indefinido & $\begin{array}{c}\text { Lei no } 11.901 \mathrm{de} \\
01.09 .95\end{array}$ & Indefinida & $\begin{array}{l}\text { Órgão } \\
\text { Estadual }\end{array}$ \\
\hline $\begin{array}{c}\text { APP DA BACIA } \\
\text { HIDROGRÁFICA RIO } \\
\text { UBERABINHA }\end{array}$ & Uberlândia, Uberaba & $\begin{array}{c}\text { Lei no } 11.931 \text {, de } \\
25.09 .95\end{array}$ & Indefinida & Indefinida \\
\hline APA SERRA DO LOPO & Extrema & $\begin{array}{c}\text { Lei no } 11.936 \text { de } \\
06.10 .95\end{array}$ & Indefinida & Indefinida \\
\hline
\end{tabular}

Quadro 12: Áreas protegidas com limites ou jurisdição indefinidos

(Fonte: legislação específica até dezembro de 1995).

Chart 12: Protected areas without defined limits or jurisdiction (Source: specific legislation till december 1995). 


\begin{tabular}{|c|c|c|c|c|}
\hline NOME & MUNICÍPIO & $\begin{array}{l}\text { LEGISLAÇÃO DE } \\
\text { CRIAÇÃO }\end{array}$ & $\begin{array}{l}\text { ÁREA } \\
\text { (ha) }\end{array}$ & JURISDIÇÃO \\
\hline APE SERRA AZUL & $\begin{array}{l}\text { Mateus Leme, Igarapé, } \\
\text { Itaúna, Juatuba }\end{array}$ & $\begin{array}{c}\text { Decreto } \mathrm{n}^{0} 20.792, \text { de } \\
08.07 .80\end{array}$ & 26.058 & COPASA \\
\hline APE VÁRZEA DAS FLORES & Contagem e Betim & $\begin{array}{c}\text { Decreto } \mathrm{n}^{0} 20.793, \text { de } \\
08.09 .80 \\
\end{array}$ & 12.300 & COPASA \\
\hline APE MUTUCA (1) & Nova Lima & $\begin{array}{c}\text { Decreto } \mathrm{n}^{\circ} 21.372, \mathrm{de} \\
01.07 .81\end{array}$ & $1.250^{*}$ & COPASA \\
\hline APE VERÍSSIMO & Ouro Branco & $\begin{array}{c}\text { Decreto } \mathrm{n}^{0} 22.055, \mathrm{de} \\
05.05 .82\end{array}$ & 2.000 & COPASA \\
\hline APE BARREIRO* & Belo Horizonte & $\begin{array}{c}\text { Decreto } n^{\circ}=22.091, \text { de } \\
08.06 .82\end{array}$ & $1.327^{*}$ & COPASA \\
\hline $\begin{array}{l}\text { APE ROLA-MOÇA } \\
\text { E BÁLSAMO }\end{array}$ & Ibirité & $\begin{array}{c}\text { Decreto } \mathrm{n}^{\circ} \mathrm{2} 2.110, \mathrm{de} \\
14.06 .82\end{array}$ & $738^{*}$ & COPASA \\
\hline APE TABOÃO & Ibirité & $\begin{array}{c}\text { Decreto } \mathrm{n}^{\circ} \mathrm{2} 2.109, \mathrm{de} \\
14.06 .82\end{array}$ & $890^{*}$ & COPASA \\
\hline APE CATARINA & Brumadinho & $\begin{array}{c}\text { Decreto } \mathrm{n}^{0} 22.096, \mathrm{de} \\
14.06 .82 \\
\end{array}$ & $480^{*}$ & COPASA \\
\hline APE FECHOS & Nova Lima & $\begin{array}{c}\text { Decreto } \mathrm{n}^{\circ} 22.327, \mathrm{de} \\
03.09 .82\end{array}$ & $476^{*}$ & COPASA \\
\hline APE RIO MANSO & $\begin{array}{c}\text { Rio Manso, Brumadinho } \\
\text { Crucilândia, Bonfim, Itatiaiuçu }\end{array}$ & $\begin{array}{c}\text { Decreto } \mathrm{n}^{0} 27.928, \text { de } \\
15.03 .88\end{array}$ & 65.778 & COPASA \\
\hline $\begin{array}{l}\text { APE CÓRREGOS FEIO, } \\
\text { FUNDO E AREIA }\end{array}$ & Araxá & $\begin{array}{c}\text { Decreto } \mathrm{n}^{\circ} 29.586, \mathrm{de} \\
08.06 .89\end{array}$ & 14.800 & COPASA \\
\hline $\begin{array}{c}\text { APE SANTA ISABEL E } \\
\text { ESPALHA }\end{array}$ & Paracatu & $\begin{array}{c}\text { Decreto } \mathrm{n}^{\circ} 29.587, \mathrm{de} \\
08.06 .89\end{array}$ & 21.600 & COPASA \\
\hline APE SOBERBO E RETIRO & Pedra Azul Cach. do Pajeu & $\begin{array}{c}\text { Decreto } \mathrm{n}^{0} 29.588, \mathrm{de} \\
08.06 .89\end{array}$ & 10.440 & COPASA \\
\hline APE TODOS OS SANTOS & Teófilo Otoni e Poté & $\begin{array}{c}\text { Decreto } \mathrm{n}^{0} 29.589, \mathrm{de} \\
08.06 .89\end{array}$ & 25.890 & COPASA \\
\hline APE CERCADINHO & Belo Horizonte & $\begin{array}{c}\text { Decreto } \mathrm{n}^{\circ} 22.327, \mathrm{de} \\
03.09 .82\end{array}$ & 247 & COPASA \\
\hline APE CONFUSÃO & São Gotardo & $\begin{array}{c}\text { Decreto } \\
\text { desapropriação } \mathrm{n}^{\circ} \\
21.344, \text { de } 19.05 .81\end{array}$ & 2.768 & COPASA \\
\hline
\end{tabular}

Quadro 13: Áreas de proteção especial - mananciais

(Fonte: legislação específica até dezembro de 1995).

Nota: (1) As APE Mutuca, Rola-Moça e Bálsamo, Catarina, Barreiro, Taboão e Fechos cobrem 1.686 ha quando retiradas as unidades Parque Estadual do Rola-Moça e Estação Ecológica de Fechos.

Chart 13: Areas of special protection - fountainheads (Source: specific legislation till december 1995).

(1) The APE Mutuca, Rola-Moça and Bálsamo, Catarina, Barreiro, Taboão and Fechos covers 1.686 ha excluding the units of Rola Moça State Park and Ecological Station of Fechos.

do solo. A amplitude de seus objetivos (proteção de mananciais, patrimônio cultural, histórico, paisagístico e arqueológico) e a conseqüente indefinição de seu objetivo prioritário de proteção de mananciais transformam-na em um instrumento muito geral para figurar como unidade de conservação.

A mesma questão se coloca para Áreas de Preservação Permanente (APP) que se adequam melhor à proteção de tipologias vegetais que se encontram dispersas do que para definir unidades de proteção (Quadro 14).

As áreas definidas como APP devem ser reenquadradas para figurarem como unidades de conservação.

As áreas indígenas, por possuírem objetivos diferenciados, não são consideradas unidades de conservação, mas foram incluídas no Cadastro já que o nível de restrição ao uso dos recursos naturais justifica sua absorção para fins de ICMS (Quadro 15).

\section{CONCLUSÃO}

A proteção das áreas naturais do Estado de Minas Gerais tem papel relevante no contexto brasileiro, tanto pela extensão territorial do Estado como pela importância de seus ecossistemas. Não sem razão, em Minas Gerais encontra-se a maior parcela da primeira área protegida no Brasil, o Parque Nacional do Itatiaia, criado em 1937.

O número de unidades de conservação e a superfície protegida, no Estado, teve um acréscimo expressivo nas décadas de 80 e 90, conforme Figura 3 e Quadro 2. Esta superfície representa $0,58 \%$ do território mineiro, com proteção integral e 2,12\% da área total do Estado, uma vez incluídas as unidades de manejo sustentado (Tabelas 1 e 2). Este percentual está bem aquém do apresentado pelo Brasil, que possui 1,8\% de seu território em unidades de proteção integral, chegando a 3,7\% com inclusão das unidades de uso sustentado, 


\begin{tabular}{|c|c|c|c|c|}
\hline NOME & MUNICÍPIO & $\begin{array}{c}\text { LEGISLAÇÃO DE } \\
\text { CRIAÇÃO }\end{array}$ & $\begin{array}{c}\text { ÁREA } \\
\text { (ha) }\end{array}$ & JURISDIÇÃO \\
\hline $\begin{array}{c}\text { ÁREA DE PRESERVAÇÃO } \\
\text { PERMANENTE GRUTA DA } \\
\text { IGREJINHA }\end{array}$ & Ouro Preto e Ouro Branco & $\begin{array}{c}\text { Decreto } n \text { o } 26.420, \text { de } \\
09.12 .86\end{array}$ & 688 & COPAM/FEAM \\
\hline $\begin{array}{c}\text { ÁREA DE PRESERVAÇÃO } \\
\text { PERMANENTE LAGOA } \\
\text { POÇO VERDE }\end{array}$ & Coromandel & $\begin{array}{c}\text { Decreto } \text { no } 29.301, \text { de } \\
16.03 .89\end{array}$ & 24 & COPAM/ \\
\hline
\end{tabular}

Quadro 14: Áreas de preservação permanente (Fonte: Legislação específica até dezembro de 1995). Chart 14: Areas of Permanent Preservation (Source: specific legislation till december 1995).

\begin{tabular}{|c|c|c|c|c|}
\hline NOME & MUNICÍPIO & $\begin{array}{c}\text { LEGISLAÇÃO DE } \\
\text { CRIAÇÃO }\end{array}$ & $\begin{array}{c}\text { ÁREA } \\
\text { (ha) }\end{array}$ & JURISDIÇÃO \\
\hline ÁREA INDÍGENA KRENAC & Resplendor & $\begin{array}{c}\text { Decreto Estadual } \mathrm{n}^{0} \\
5.462, \text { de1 } 0.12 .20\end{array}$ & 3.983 & FUNAI \\
\hline ÁREA INDÍGENA XACRIABÁ & $\begin{array}{c}\text { Itacarambi, São João das } \\
\text { Missões }\end{array}$ & $\begin{array}{c}\text { Decreto Federal } \mathrm{n}^{0} \\
94.608, \text { de } 14.07 .87\end{array}$ & 46.800 & FUNAI \\
\hline $\begin{array}{c}\text { ÁREA INDÍGENA FAZENDA } \\
\text { GUARANI }\end{array}$ & Carmésia & $\begin{array}{c}\text { Decreto Federal } \mathrm{n}^{\circ} 270 \\
\text { de } 29.10 .91\end{array}$ & 3.270 & FUNAI \\
\hline $\begin{array}{c}\text { ÁREA INDÍGENA } \\
\text { MAXACALIS }\end{array}$ & $\begin{array}{c}\text { Bertópolis, Santa Helena de } \\
\text { Minas }\end{array}$ & $\begin{array}{c}\text { Portaria } \mathrm{n}^{0} 317 / \mathrm{MJ} \text { de } \\
14.08 .93\end{array}$ & 5.306 & FUNAI \\
\hline
\end{tabular}

Quadro 15: Áreas indígenas (Fonte: legislação específica até dezembro de 1995).

Chart 15: Native Reserves (Source: specific legislation till december 1995).

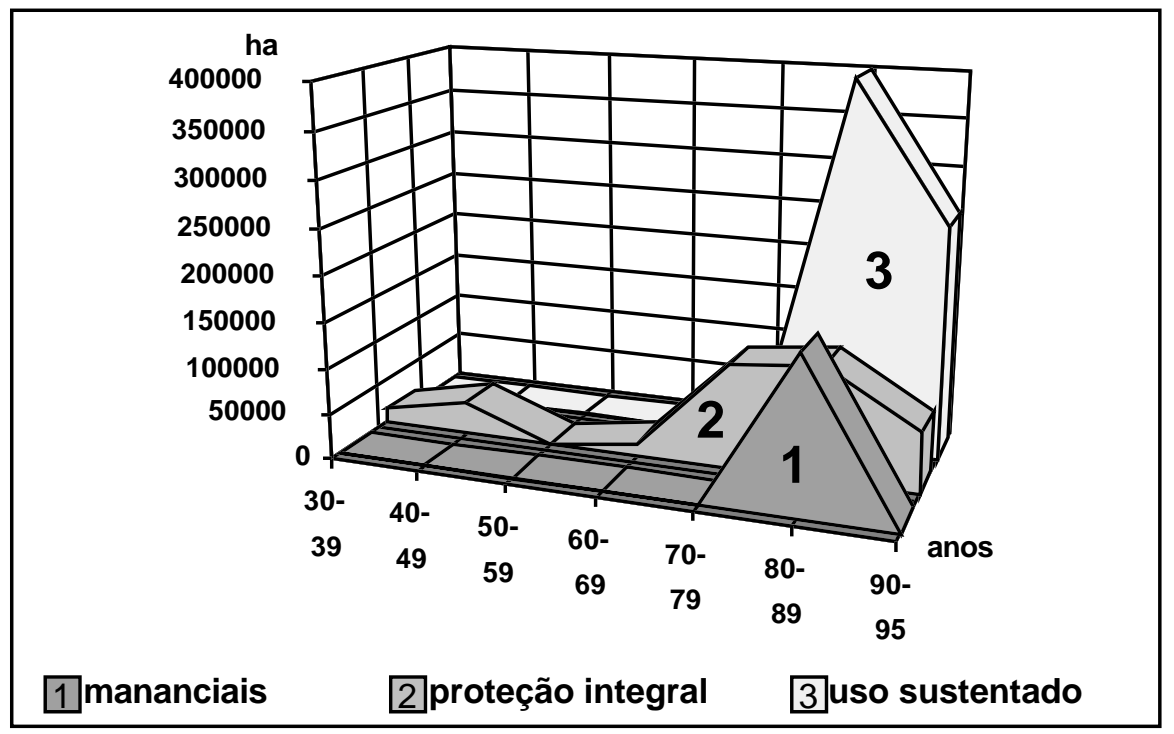

Figura 3: Evolução das dimensões protegidas em Minas Gerais (Fonte: FEAM. Cadastro de UC de Minas Gerais, dezembro de 1995).

Figure 3: Evolution of size (in ha) of protected areas in Minas Gerais (Source: FEAM. Cadastro de Unidades de Conservação, december 1995). 1 = fontainheads; 2 = allores protection; 3 = sustained use.

que é ainda inferior ao apresentado pela média mundial - 5\% e da América Latina - 6,7\% (WWF 1994).

Além da análise dos dados da superfície protegida, torna-se necessário avaliar a representatividade desta área quanto aos biomas existentes no território mineiro, bem como o desempenho de cada unidade.

O Cadastro de Unidades de Conservação, que fornece até o momento os dados relativos às unidades federais, estaduais e particulares (Quadros 3 a 14) e a cartografia dos limites destas áreas representam a base fundamental para esta avaliação. Este cadastro contribui, assim, para a elaboração de um plano estadual que defina as metas, conceitos e critérios para a seleção de novas áreas e adequação das existentes, de forma que os componentes unitários sejam complementares em suas funções e colaborem para o objetivo global da conservação dos recursos naturais.

\section{4 - REFERÊNCIAS BIBLIOGRÁFICAS}

BRASIL, Câmara dos Deputados, Comissão de Defesa do Consumidor, Meio Ambiente e Minorias. Projeto de Lei $n^{o}$ 2.892 de 1992, dispõe sobre os objetivos nacionais de conservação da natureza, cria o Sistema Nacional de Unidades de Conservação, estabelece medidas de preservação da 
diversidade biológica e dá outras providências. Brasília, 1992.

BRASIL, Câmara dos Deputados, Comissão de Defesa do Consumidor, Meio Ambiente e Minorias. Substitutivo ao Projeto de Lei $n^{\circ} 2.892$ de 1992, institui o Sistema Nacional de Unidades de Conservação e dá outras providências. Brasília, 1994.

BRASIL. Decreto $n^{\circ} 98.914$ de 31 de janeiro de 1990, dispõe sobre a instituição, no território nacional, de Reservas Particulares do Patrimônio Natural, por destinação do proprietário. Brasília, 1990.

BRASIL, Ministério da Agricultura, Instituto Brasileiro de Desenvolvimento Florestal, Fundação Brasileira para a Conservação da Natureza. Plano do sistema de unidades de conservação do Brasil, II Etapa. Brasília, 1982.

MILANO, M. S. Unidade de conservação: conceitos e princípios de planejamento e gestão. Brasília: MHU/SEMA/Secretaria Adjunta de Ecossistemas. 1988 (não publicado).

MILANO, M. S. Curso sobre manejo de áreas naturais protegidas. Curitiba : Universidade Livre do Meio Ambiente, 29/05 a 04/ 06 de 1995 (não publicado).

MINAS GERAIS. Lei $n^{\circ} 10.561$ de 27 de dezembro de 1991, Decreto $n^{o} 33.944$, de 18 de setembro de 1992, dispõe sobre a política florestal do Estado de Minas Gerais. Belo Horizonte, 1991

MINAS GERAIS. Resolução no 002/95 de 07 de dezembro de 1995, divulga dados cadastrais referentes às unidades de conservação estaduais, federais e particulares situadas no Estado de Minas Gerais. Belo Horizonte, 1995.

MINAS GERAIS. Lei $n^{\circ} 12.040$ de 28 de dezembro de 1995, dispõe sobre a distribuição da parcela de receita do produto da arrecadação do ICMS pertencentes aos municípios de que trata o inciso II do parágrafo único do artigo 158 da Constituição Federal, e dá outras providências. Belo Horizonte, 1995.

MOORE, A. e ORMAZÁBAL, C. Manual de planificacion de sistemas nacionales de áreas silvestres protegidas en América Latina: metodologia y recomendaciones. Santiago, Chile: Oficina regional de la FAO para América Latina y el Caribe, 1988

PARANÁ, Secretaria de Estado do Desenvolvimento Urbano e do Meio Ambiente, Coordenadoria de Estudos e Defesa do Meio Ambiente. Coletânia de legislação ambiental: federal e estadual. Curitiba: Imprensa Oficial do Paraná, 1990.

UNIÃO INTERNACIONAL PARA A CONSERVAÇÃO DA NATUREZA E DOS RECURSOS NATURAIS - IUCN. Estratégia mundial para a conservação: a conservação dos recursos vivos para um desenvolvimento sustentado. São Paulo: CESP, 1984.

WORLD WILDLIFE FUND - WWF. Workshop: "Políticas de unidades de conservação. Brasília, 29/11 a 02/12 de 1994 (não publicado). 